\section{Drought or Wet Assessment of Daily Rainfall Pattern of the Budhi Gandaki River Basin, Nepal: Standardized Precipitation Index Approach using Probabilistic Model \\ Rajendra Man Shrestha}

Submitted: 30 August 2020; Accepted: 9 December 2020

Published online: 18 December 2020

DOI: https://doi.org// 0.3 | 26/njs.v4i0.33497

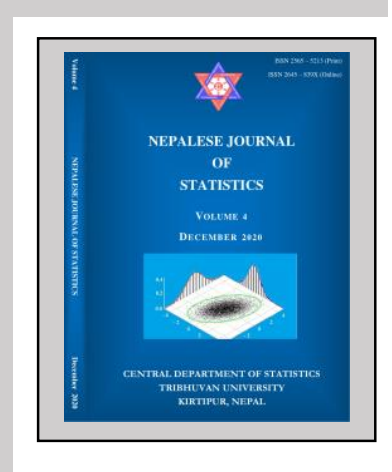

\title{
ABSTRACT
}

Background: Rainfall is a natural phenomenon. Dramatic changes in the rainfall pattern lead to extreme climatic or hydrological events like flash floods, or floods, landslides or severe drought events at any parts of the world.

Objective: The objective of this study aims to perform analysis of drought/ wet for fifteen meteorological /hydrological stations distributed over the Budhi Gandaki River Basin, Nepal.

Materials and Methods: The Kolmogorov-Simonov test, Anderson-Darling test and Chi-square test are used for testing of the hypothesis of goodness of fit supported by the q-q plot (or p-p plot), cumulative distribution function plot and probability density function plot. The standardized precipitation index is a widely used to develop the index to monitor the dryness/wetness in a given day.

Results: Johnson SB distribution and Weibull distribution were fitted to the daily rainfall across the fifteen stations.

Conclusion: There were some episodes of moderate drought events across six stations. Similarly, there were a moderate type of wetness across five stations. The rest of the stations had a majority of near normal days out of 135 I 4 days.

Keywords: Climate change, drought, floods, landslides, maximum likelihood estimation, probability distribution, rainfall, standardized precipitation index.

Address correspondence to the author: Padmakanya Multiple Campus, Tribhuvan University, Kathmandu, Nepal. E-mail: rajendramanshrestha65@gmail.com 


\section{INTRODUCTION}

Rainfall in a region is a natural phenomenon and varies according to season of the Earth. Dramatic changes in the rainfall pattern lead to an extreme climatic or hydrological events like flash floods, or floods, landslides or severe drought events at any parts of the world (Shrestha et al., 2017). Furthermore, global or local climate change has a significant effect on the rainfall and its cycle with increased climatic variability (Hansen et al., 20l0). Depending on the perspective of water users, managers, private and public agencies, Pereira et al., (2002) stated that drought is considered as a temporary natural imbalance of water availability. It consists of a persistent lowerthan-average precipitation. Then it leads to uncertain frequency, duration and severity. Consequently, there will be resulting in deficit of water resources, and then reduce carrying capacity of the ecosystems leading to adverse impact on environment, society, culture, political and other functions of the region (Deka, Boraj, \& Kakaty, 2009). Drought is a silent and pervasive hazard and happens due to the deficit of water availability (Shrestha et al., 20l4). According to Obasi (1994), approximately 85 percent of natural disasters are all associated with the droughts, which are usually considered as one of the most complicated and least understood natural hazards. Among such hazards, it is experienced that drought starts slowly without warning, for example, it may occur as below-average rainfall within a normal part of rainfall (Sigdel \& Ikeda, 20I0) or it may gradually turn into hazardous event and last for significantly longer period of time encapsulating large spatial parts (Shrestha et al., 20I4).

According to several research articles, happening of such devastating drought events in many parts of the world, including Asia have faced a significant decline in the agricultural production due to the increased frequency and severity of drought (Sigdel \& Ikeda, 20I0). Sigdel and Ikeda (2010) had also mentioned about the drought happening events in Nepal with some spatial variation. Further, Shrestha et al. (2016) has investigated and found that the summer season of 2004, 2005, 2006 and 2009; and also winters of 2006, 2008 and 2009 were the worst widespread droughts in drought risk assessment in central Nepal. Climate variables like high temperature, high wind and low relative humidity may pose as causative factors of drought in many parts of the world but among them rainfall is considered as the primary climate variable because it may control the formation and persistence of drought condition and hence further aggravate severity of the drought in the region (Sigdel \& Ikeda, 2010). Drought is a natural event of unpredictable occurrence, but of recognizable recurrence disaster. So, it is important to identify the low predictability of drought and extreme rainfall causing huge devastating floods that change into a hazard and a disaster. This extreme events make to assess the rainfall pattern by developing prediction tools through probabilistic approach to measure its uncertainty (Wilhite et al., 2000).

Summer monsoon ( $80 \%$ of total precipitation in Nepal) and winter are two main seasons associated with major crop productions in Nepal, e.g., rice and wheat. Precipitation is a dominant water source for the production in Nepal. It is also the same for the region of the Budhi Gandaki River Basin though it is the snow-fed river. Hydroelectricity, drinking water and irrigation are some 
of the main factors that can make better livelihood of people in Nepal. Thus, small sign of happening of drought may lead to serious consequences on the national economy for the short or the long period (Sigdel \& Ikeda, 2010). Although there have been some studies on rainfall patterns over Nepal (Shrestha, 2000, Shrestha \& Aryal., 2010) the study concerning on drought/extreme wet is found limited, and more specifically for the region: the Budhi Gandaki River Basin, Nepal. At the same time, there have been no sufficient studies available for the drought assessment in connection with future climate scenarios in Nepal (Shrestha et al., 2017). In the view of understanding the adverse consequences of drought/extreme wet in the region, it is necessary to monitor and assess the drought/extreme wet situation so that policy makers, managers and planners and concerned government agencies could take required action timely to mitigate possible consequences by drought.

In order to monitor and warn about drought/extreme wet, researchers or authors like meteorologists and hydrologists have developed indices, which depend on hydro-meteorological parameters or rely on probabilities of drought occurrence (Vogt and Somma, 2000; Hayes, 2006). Drought indices based on one or more climate variables are generally applicable to identify and assess drought at different time scales. The Standardized Precipitation Index (SPI) (McKee et al. $(1993,1995)$ as widely used, is simple and allows a reliable and relatively easy comparison between different locations and climates. Thus, local and regional drought indices have been developed and applied by many authors. Hayes (1999) presents a compilation of several local indices and analyses the respective advantages and disadvantages. Guttman (1998) recently compared the Palmer Drought Index (PDI) with the Standardized Precipitation Index (SPI). Limitations on the use of PDI to Mediterranean regions have been shown by Cancelliere et al. (1996). However, the advantage of the Standardized Precipitation Index just requires precipitation as an input. Thus, this study aims to perform an in-depth analysis of hydrological drought/Extreme wet using the standardized precipitation index approach through the probabilistic model for fifteen meteorological/hydrological stations distributed over the Budhi Gandaki River Basin, Nepal. It is expected that this study could be helpful to support water resources management and facilitate the Budhi Gandaki Hydroelectric Project and irrigation under drought/extreme wet. It is worth to introduce about the Budhi Gandaki Hydroelectric Project as it may influence by the impact of hazard of extreme drought/extreme wet at present or in future. This study may help take timely action for safeguarding the project if there would happen that hazards in future.

\section{Budhi Gandaki hydroelectric project}

This is the proposed storage hydropower plant project of annual generation of 3, 383 GWh in Nepal developing under Nepal Electricity Authority (NEA). It is located on the Budhi Gandaki River (of catchment area of $5,000 \mathrm{~km}^{2}$ ), approximately $2 \mathrm{~km}$ upstream of its confluence with Trishuli River, about $55 \mathrm{~km}$ west of Kathmandu (Wikipedia, 2020). 


\section{MATERIALS AND METHODS \\ Study area}

The Budhi Gandaki River in Figure I(Shrestha et al., 20I6) is a tributary of the Gandaki River in Nepal. It meets the Trishuli River at Benighat of Dhading and Gorkha District in the central of Nepal. The river originates from two main branches, one from the Lark Himal and the other, the Mowang Khola, from the Ladak Himal in Tibet. After the confluence of these two branches the river flows about $120 \mathrm{~km}$ to the south before it joins the Trishuli River. The Basin in Tibet is approximately $1750 \mathrm{Km}^{2}$. The total Basin of the basin at dam site is about $5370 \mathrm{~km}^{2}$ (Gaudel, P., 2013). This paper attempted to deal with daily drought or wet pattern of 15 different stations distributed over the Budhi Gandaki River Basin in Nepal. This study may identify a very short run impact due to daily rainfall patterns of the period: 198I-20I7 with reference to its extreme event like drought/wet or precisely severity of drought/wet, or etc. under the normal condition of the climate of the Budhi Gandaki River Basin.

\section{Data}

The daily rainfall data were obtained from Department of Hydrology and Meteorology Department, Kathmandu, Nepal for 15 different stations distributed over the Budhi Gandaki River Basin. The data range from 198I to 2017. The data were cleaned if there were some inconsistency or errors. The missing values were replaced using arithmetic mean of the data from neighboring stations as far as possible.

\section{Sample data}

According to SPI User Guide of World Meteorological Organization Guttmann (1994), the sample data needs at least 20-30 years of monthly data, with 50-60 years (or more) being optimal and preferred. The sample size for the monthly data seems to be 240-360 (total number of months). It is 50-60 (or more) (Total number of years) for the yearly data. The monthly data contains the total rainfall for a month. The yearly data contains the total rainfall for a year. bBut this study is using a daily rainfall data for a period of 1981-2017 (or 36 years). Then, the sample size becomes 135 I4 (total number of days). It means that the guide line seems to support that the sample data are sufficient for assessing the rainfall pattern over the 15 stations of the Budhi Gandaki River basin.

\section{Steps}

According to Guttmann (1998, 1999), the first step is to fit a probability distribution of a random variable, say $X$. The random variable $X$ was supposed to assume a long-term series of daily rainfall observations. The next step is to apply the formula proposed by Abramowitz and Stegun (1965). The final step is then to calculate the Standardized Precipitation Index (SPI) for daily rainfall data. This study has attempted to select one of best suitable theoretical/probability distribution like Johnson SB, Gamma, Log-normal, Logistic, Weibull and Generalized Extreme Value (GEV) distributions. 


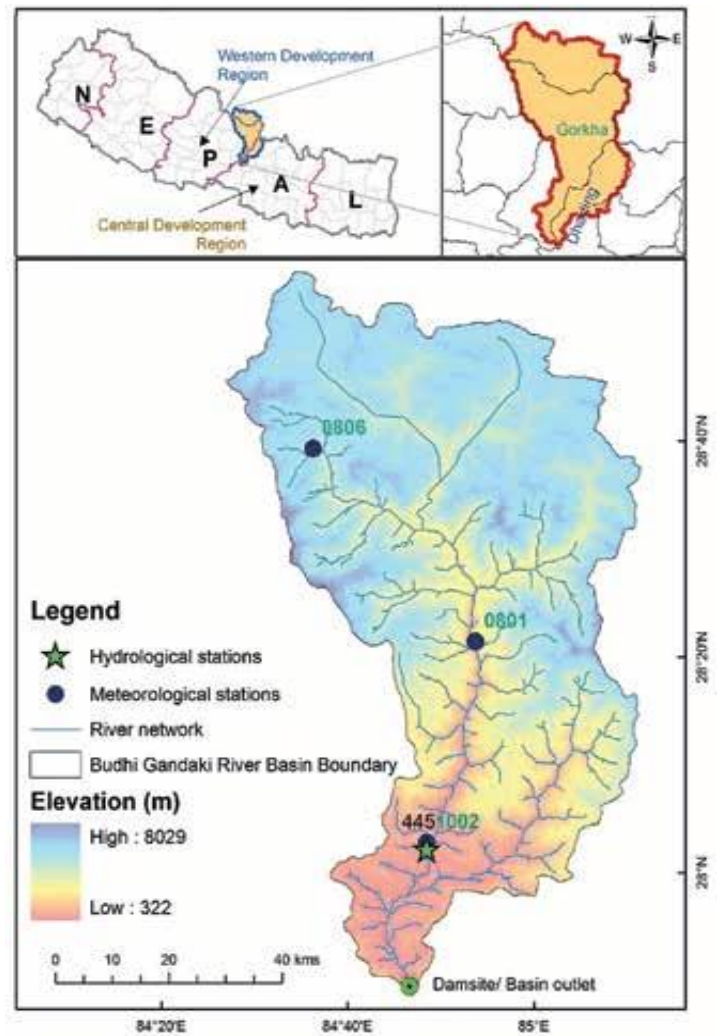

Fig. I. Budhi Gandaki River Basin

\section{Estimation}

The EasyFit 5.5 professional software I, the evaluation version (David, G. B., 2012) was used to select the best on among them using estimation methods like L-Moments, Maximum likelihood estimation (MLE) or Least-Square method Guttmann (1999) and Vicente-Serrano, Beguria, and Looez-Mareno (2010). There are estimated values of the parameters of the selected theoretical distributions in Table 2.

\section{Testing of hypothesis}

The Kolmogorov-Simonov (KS) test, Anderson-Darling (AD) test and Chisquare test are used for testing of the hypothesis of goodness of fit in EasyFit 5.5 Professional. The software gives a rank I to the best fit one. Then it gives a rank 2 and so on to other theoretical distributions according to the types of hypothesis test. The hypothesis was set up as null hypothesis $\mathrm{H}_{0}$ : $A$ theoretical distribution is fitted to the daily rainfall data versus alternative hypothesis $\mathrm{H}_{1}$ : A theoretical distribution is not fitted to the daily rainfall data. Table 2 has displayed the selected at most two distributions for the daily rainfall data of 15 different stations (See also Supplementary A of Supplementary material).

\section{Quantile-Quantile plots}

There are also different types of plot like q-q plot or p-p plot, cumulative distribution function plot and probability density function plot in the software. Among them, the q-q plot is mostly used plot to identify better fitting of the observed data to the given probability distribution.

\section{Probability distribution}

This step, briefly includes the distribution function or cumulative distribution function (cdf), $F(x)$, defined for $x>0$. However, for $x<0$, cdf of $x$ is adjusted to $H(x)=q+(I-q) F(x)$, where ' $q$ ' is the probability of no precipitation or zero. ' $q$ ' is empirically measured as the ratio of the number of events of no rain to the total number of events in a given time-series. The cumulative probability $H(x)$, is then transformed to the standard normal distribution, $\Phi(z)$ with zero mean and unit variance of a new random variable, $Z$ (Edwards \& McKee, 1997). Thus, this $Z$ is a Standardized 
Precipitation Index (SPI). However, this SPI obtained by above simple approach is easy but not practical for large number of data points (Sigdel \& Ikeda, 20I0). For this study, the approximation method is used to compute the SPI recommended by Abramowitz and Stegun (1965).

\section{Standardized precipitation index}

The Standardized Precipitation Index is the simplest technique to compute a drought index among all indicators like Palmer Drought Severity Index and Standardized Precipitation Evapotranspiration Index. It only requires the precipitation/rainfall at a station. It was designed by McKee, Doesken, and Kleist (1993). Thus, it is widely used as a quantitative measure of drought in its forecasting, frequency analysis, spatiotemporal analysis and climate change impact studies (Mishra \& Singh, 2010). It is the simplest as it requires only precipitation as input. It is generally determined for trimonthly, quarterly, half yearly, yearly and 2-yearly (Edwards \& McKee, 1997). It can be defined for any timescale of interest and further, is comparable in both time and space. Its additional advantage is that it is not affected by geographical and topographical differences (Lana, Serra, \& Burgueno, 200I). In this study, the SPI is calculated for a daily rainfall data to identify a daily drought or wet pattern for 15 different stations. For this study, the approximation method to compute the SPI (Abramowitz and Stegun, 1965) is given below.

$$
\begin{aligned}
& S P I=Z=-\left(t-\frac{c_{0}+c_{1} t+c_{2} t^{2}}{1+d_{1} t+d_{2} t^{2}+d_{3} t^{3}} \text { for } 0<H(x)<0.5 \text { where }\right) \\
& t=\sqrt{\operatorname{Ln}\left(\frac{1}{(H(x))^{2}}\right) \text { for } 0<H(x)<0.5} \\
& S P I=Z=+\left(t-\frac{c_{0}+c_{1} t+c_{2} t^{2}}{1+d_{1} t+d_{2} t^{2}+d_{3} t^{3}} \text { for } 0.5<H(x)<1.0 \text { where }\right) \\
& t=\sqrt{\operatorname{Ln}\left(\frac{1}{1-(H(x))^{2}}\right)} \text { for } 0.5<H(x)<1.0 \\
& c_{0}=2.5 I 5517, c_{1}=0.802853, c_{2}=0.010328, d_{1}=1.432788, d_{2}=0.189269, d_{3}=0.001308 .
\end{aligned}
$$

The SPI so computed is considered to be a normally distributed random variable. Then it can be interpreted as a number of standard deviations that the observed value would deviate from the very short-term mean for a daily rainfall data. For its detail interpretation, McKee et al. (1993) had presented the drought/wet categories based on the SPI in Table I. 
Table I. Drought/wet categories for SPI.

\begin{tabular}{ll}
\hline \multicolumn{1}{c}{ SPI } & Drought Category \\
2 or above & Extreme wet \\
$1.50-1.99$ & Very wet \\
$1.00-1.49$ & Moderate wet \\
-0.99 to 0.99 & Near normal \\
-1.00 to -1.49 & Moderate drought \\
-1.5 to -1.99 & Severe drought \\
-2.00 or less & Extreme drought \\
\hline
\end{tabular}

Source: McKee et al. (1993)

\section{RESULTS}

\section{Fitting probability distribution}

Developing of the standardized precipitation index requires the daily rainfall data to be fitted to suitable probability distribution using maximum likelihood estimation method (however, some data may require other estimation method too) (Rossi, 2018). There are several methods to test whether a given data is fitted to a specific theoretical distribution. In this paper, there are three methods, namely Kolmogorov-Smirnov Test, Anderson-Darling Test and Chi-squared test considered for a goodness-of-fit test (GOF). EasyFit 5.5 Professional (Evaluation version) was used to estimate the parameters and fitting the distribution of the daily rainfall data. The results are presented in Table 2.

Table 2. Suitable probability distribution fitting to daily rainfall data across 15 meteorological stations of Budhi Gandaki Basin.

\begin{tabular}{|c|c|c|c|c|c|c|c|c|}
\hline \multirow{2}{*}{ Stations } & \multirow{2}{*}{$\begin{array}{l}\text { Probability } \\
\text { Distribution }\end{array}$} & \multicolumn{7}{|c|}{ Parameters } \\
\hline & & $\mu$ & $\sigma$ & k & $\gamma$ & $\delta / \alpha$ & $\lambda / \beta$ & $\xi$ \\
\hline Arughat D. Bazar & Normal & 6.449 & 13.839 & & & & & \\
\hline Arughat D. Bazar & Johnson SB & & & & 2.259 & 0.6281 & $|34.2|$ & -2.381 \\
\hline Chame & Normal & 8.162 & 18.25 & & & & & \\
\hline Chame & Johnson SB & & & & 2.847 & 0.7689 & 273.58 & -4.808 \\
\hline Chhekampar & Logistic & 3.225 & 3.743 & & & & & \\
\hline Chhekampar & Johnson SB & & & & 8.580 & 1.0137 & 15479.0 & -2.078 \\
\hline Dhading & Normal & 8.285 & |7.37| & & & & & \\
\hline Dhading & Johnson SB & & & & 2.477 & 0.7523 & 193.18 & -4.917 \\
\hline Dhunche & $\begin{array}{l}\text { Gen. Extreme } \\
\text { Value }\end{array}$ & 0.3406 & 0.73238 & 0.6355 & & & & \\
\hline Dhunche & Weibull & & & & 0 & 0.4306 & 0.8626 & Contd. \\
\hline Dhunibesi & $\begin{array}{l}\text { Gen. Extreme } \\
\text { Value }\end{array}$ & 0.3493 & 0.75628 & 0.6358 & & & & \\
\hline
\end{tabular}




\begin{tabular}{|c|c|c|c|c|c|c|c|c|}
\hline Dhunibesi & Weibull & & & & 0 & 0.4254 & 0.8726 & \\
\hline Gharedhunga & $\begin{array}{l}\text { Gen. Extreme } \\
\text { Value }\end{array}$ & 0.8688 & 0.51863 & 0.5186 & & & & \\
\hline Gharedhunga & Johnson SB & & & & 3.936 & 1.0837 & 183.57 & -2.868 \\
\hline Gorkha & Logistic & 2.7412 & 3.1162 & & & & & \\
\hline Gorkha & Johnson SB & & & & 4.506 & 1.0076 & 269.71 & -2.073 \\
\hline Jagat & Logistic & 4.0858 & 4.8703 & & & & & \\
\hline Jagat & Johnson SB & & & & 3.664 & 0.8978 & 238.49 & $-2.76 I$ \\
\hline Khudi & Logistic & 10.313 & 10.313 & & & & & \\
\hline Khudi & Johnson SB & & & & 2.797 & 0.7872 & 265.38 & -4.931 \\
\hline Larke & Wakeby & & & & 2.122 & 0.4346 & -0.5391 & \\
\hline Larke & Johnson SB & & & & 4.532 & 1.0205 & 278.71 & -1.852 \\
\hline Nuwakot & Normal & 5.4377 & II.387 & & & & & \\
\hline Nuwakot & Johnson SB & & & & 2.248 & 0.6870 & 107.75 & $-2.78 \mid$ \\
\hline Pansayakhola & Normal & 8.2859 & $|7.37|$ & & & & & \\
\hline Pansayakhola & Johnson SB & & & & 2.477 & 0.7523 & 193.18 & -4.917 \\
\hline Samdo D. Bazar & Normal & 4.5689 & 11.879 & & & & & \\
\hline Samdo D. Bazar & Johnson SB & & & & 2.655 & 0.6225 & 166.12 & -1.907 \\
\hline Timure & Normal/ & 13.839 & 6.449 & & & & & \\
\hline Timure & Johnson SB & & & & 2.259 & $0.628 I$ & $|34.2|$ & -2.381 \\
\hline
\end{tabular}

Table 2 shows at most two distributions along with the estimates of their respective parameters, fitted to the daily rainfall data collected from 15 different meteorological stations distributed over the Bhudigandi Basin. These stations have encapsulated all the tributaries of the river as far as possible. The fitted distributions were based on any one of above three goodnessof-fit methods. Usually the insignificant $p$-values of the test-statistic was used to accept the null hypothesis of getting fitted to a given probability distribution. However, in the study, there is controversy in using only the p-value approach in decision making for the fitting (GOF) (Valentin, Fränzi, \& Tobias, 2017). So, there is an alternative way, i.e.; use of graphical techniques to take the final decision. There are several graphical techniques to explore the better fit of the data to the given probability distribution. In this paper, a $\mathrm{Q}-\mathrm{Q}$ (quantile-quantile) plot was used for final decision because all the three methods of GOF have assigned rank $I$ to different probability distribution. In Table 2, there are two distributions selected for each of 15 stations. The first one was based on the $p$-value approach under the Kolmogorov-Smirnov test, which has assigned rank I to a particular distribution compared to both Anderson-Darling test and Chi-square test. And the second one was based on the Q-Q plot. Here one of 15 figures is presented for illustration. The remaining figures can be availed on demand due to the space constraint of this paper.

The $p$-value of the Kolmogorov-Smirnov test had showed the best selection of the normal distribution fitted to the daily rainfall data at Arughat station. But Figure 2 has declared that the 
Q-Q plot of Johnson SB distribution is very much close to the diagonal line of the plot among all four plots. Thus, this distribution was taken as a better fit to the data despite the normal distribution (whose Q-Q plot is very far from the line). In the similar fashion, this distribution was selected for the stations Chame, Chhekampar, Dhading, Gharedhunga, Gorkha, Jagat, Khudi, Larke, Nuwakot, Pansayakhola, Samdo D. Bazar and Timure. Similarly, Inv. Gaussian fitted to the rainfall data at stations, Dhunche and Dhunibesi. However, the q-q plots for the rest of the stations are not shown here for the sake of limited space available for this paper.

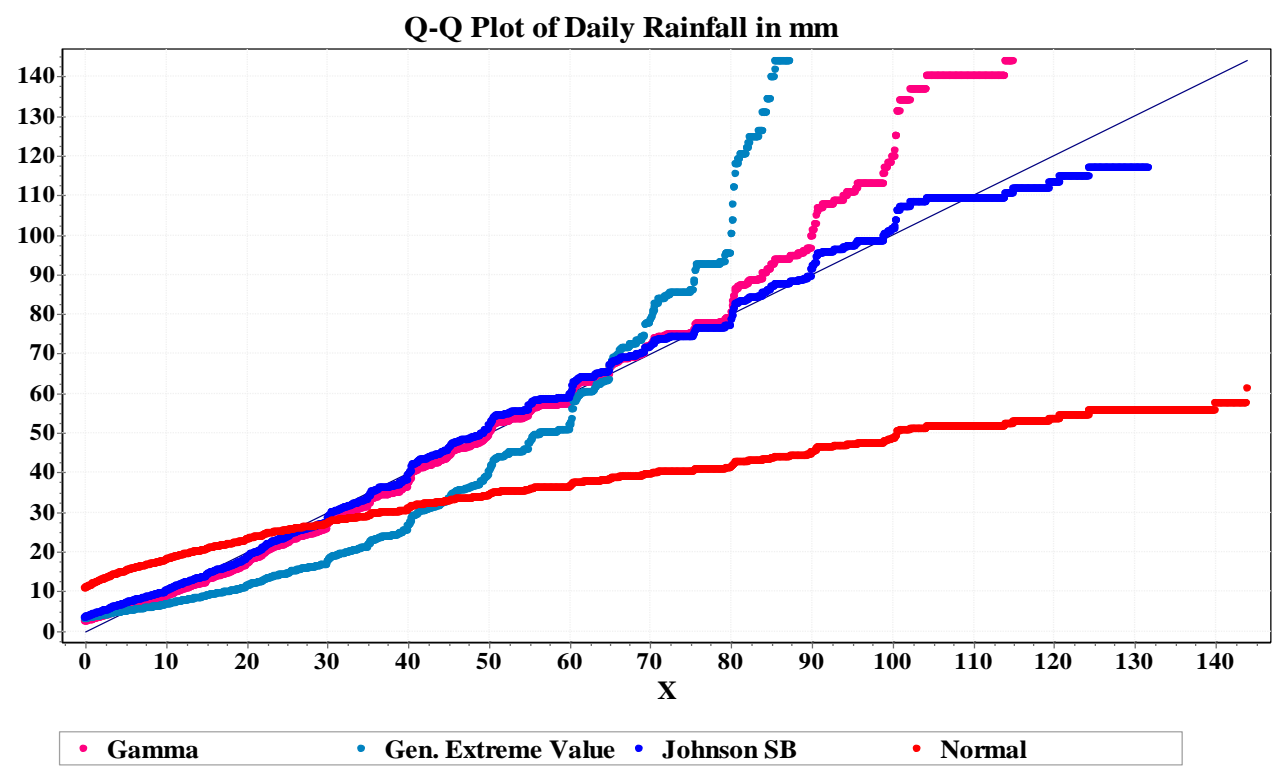

Fig. 2. Five $q-q$ plots of the daily rainfall are corresponding to Gamma, Gen. extreme value, Johnson SB and Normal distributions at Arughat station.

\section{Standardized precipitation index}

The Standardized Precipitation Indices (SPI) were computed for all 15 stations. Some part of SPI is presented in Table 3. Based on the nature of the SPI, the drought/wet categories were developed using Table I. Frequency analysis was used for the results of each station for their drought/wet category to understand the pattern of the daily rainfall distribution over entire the Budhi Gandaki River Basin through 15 stations. Table 3.a - Table 3.o display the categories from extremely wet to extreme drought for 15 separate stations. The occurrence of type of drought/wet day was presented in terms of a number (or percentage) of days out of total days of I35I4 from year 198I to the year 2017. The pattern of daily rainfall was analyzed on monthly basis according to Table 3.(a-o). The analysis was descriptive or analytical taking a number of days of I35 4 days of 38 years. This study has focused mainly on the days of drought and wet in all the months. Extreme (or very) wet and extreme (or very) drought figures are not shown here due to negligible figure from those tables. From Table 3.a to Table 3.o, it is seen that no stations had events of extreme wet and extreme drought days during the year: 1981-2017. This is a better sign 
of non-occurrence of extreme events like drought or extreme floods. Though the Budhi Gandaki River is a snow-fed, some of its tributaries may be the rain-fed streams. Such rivers may be affected by drought events, especially in dry-season like winter and pre-monsoon. Table 3.a - 3.o present the rainfall pattern of the 15 meteorological stations distributed over the Budhi Gandaki River Basin (See Supplementary B of Supplementary material). These tables have depicted change in the pattern due to spatial variation and monthly (seasonal) variations.

\section{Number of days far from near normal days}

When a number of days far from near normal days are compared across the stations in total of 13514 days of 36 years, there is the highest figure, $25.03 \%$ seen in Gharedhunga. It is followed by Larke (18.75\%), Dhunche (18.48\%), and Dhunibesi (17.95\%). There is the smallest figure, 3.34\% seen in Samdobazar Dhading and Pansayakhola. It is followed by Dhading and Pansayakhola (each $3.41 \%$ ) and Arughat (4.38\%). When a number of moderately drought days are compared across the 15 stations in each of their total of non near normal days, there is the highest figure, $90.15 \%$ seen in Dhunibesi. It is followed by Chhekampar and Dhunche (each $89.94 \%$ ), and Gharedhunga (86.43\%). There is the smallest figure, $22.19 \%$ seen in Dhading and Pansayakhola each. It is followed by Nuwakot (28\%) and Arughat (32.77\%). But Samdobazar had no a moderately drought days. When a number of moderately wet days are compared across the 15 stations in each of their total of non near normal days, there is the highest figure, $82.29 \%$ seen in Samdobazar. It is followed by Dhading and Pansayakhola (each 66.39\%), and Nuwakot (63.37\%). There is the smallest figure, $3.26 \%$ seen in Dhunche. It is followed by Dhunibesi (3.38\%). When a number of very wet days are compared across the 15 stations in each of their total of non near normal days, there is the highest figure, $14.91 \%$ seen in Timure. It is followed by Arughat (14.86\%) and Samdobazar (14.53\%). There is the smallest figure, $1.69 \%$ seen in Gharedhunga. It is followed by Larke $(2.45 \%)$ and Jagat (3.1 I\%).

\section{Monthly highest moderate drought days}

When a monthly drought day is compared across 15 stations with respect to the highest moderate drought, Dhunche (14.02\% on October) is seen as a very first station. It is followed by Dhunibesi (13.52\% on May), Jagat (I3.09\% on October) and Gharedhunga (12.57\% on October). Moreover, Samdobazar has not shown any drought days. Likewise, Dhading and Pansayakhola have the lowest drought days of $4.68 \%$ on April each. It is followed by Arughat (4.89\% on April) and Timure (4.92\% on April).

\section{Monthly highest moderate wet days}

When a monthly wet day is compared across 15 stations with respect to the highest moderate wet, Samdobazar ( $24.95 \%$ on July) is seen as a very first station. It is followed by Dhading ( $23.22 \%$ on July), Pansayakhola ( $23.22 \%$ on July). On the same fashion, Dhunche has the lowest moderate wet days of $1.08 \%$ on March. It is followed by Dhunibesi (I.15\% on August). 


\section{Monthly highest very wet days}

When a monthly wet day is compared across 15 stations with respect to the highest very wet, Samdobazar ( $4.99 \%$ on July) is seen as a very first station. It is followed by Timure ( $4.92 \%$ on July) and Arughat (4.89\% on July). On the same manner, Larke has the lowest very wet days of $0.39 \%$ on January. It is followed by Gharedhunga ( $0.44 \%$ on August). Moreover, Dhunche and Dhunibesi have not been experiencing a very wet day.

\section{DISCUSSION}

Topcu, \& Seckin (2016) had studied about drought analysis using standardized precipitation index (SPI) based on the monthly precipitation of II meteorological stations in the Seyhan Basin. They found that the wettest station is Uluisla and the most drought station is Karaisali with respect to the average SPI. In carrying out studies, L-moments method was used to estimate the parameters. They found the Pearson Type 3 distribution most suitable for two homogeneous subbasins. But the Generalized Normal distribution was found suitable to the whole basin. Thomas, Nayak, \& Narayn (2015) carried out the study about the spatiotemporal variations of the drought scenario over the Bundelkhand region in central India using SPI. The results show that the frequency and severity of droughts have increased over the last decade in the Bundelkhand region. The analysis showed that it has varied between once in 3 years and once in 5 years. With the 3month SPI for many blocks in the region indicated statistically significant the increasing severity of drought during the principal rainy months (July, August, and September).

The study was carried out to identify the extremes of long term distribution of rainfall in drought using SPI in drought hit hot semiarid agro ecoregion of Yavatmal district, Maharashtra, India (Bhaskar et. al., 20I8). The results of the data of the period of I97I to 2005 showed that the week wise SPI values for 35 years were categorized into 6 classes. Then, there were near normal dry periods occurring $63 \%$, followed by $19.73 \%$ of normal wet periods, $5.71 \%$ of severely wet periods, $4.72 \%$ of moderately wet periods. It was still followed by $4.28 \%$ of extremely wet periods and $2.41 \%$ of moderately dry weeks. These studies with the use of the SPI have justified that the rainfall analysis for drought or wet are most relevant to the Budhi Gandaki River Basin in Nepal. Although the way of analysis from above studies is relatively different, the results and findings are more relevant to this study.

\section{CONCLUSION}

Out of 15 stations, Gharedhunga has been experiencing the highest percentage of non near normal days. Against it, Arughat has been experiencing the smallest percentage of that day. Then Dhunibesi is the first station by moderately drought days. Samdobazar is the first station by moderately wet days. Samdobazar has also not been experiencing drought days at all. Finally, Timure has a long experience of very wet days. However, a very wet day is not seen effective in all the stations as compared to other hydrological events. The findings have shown a greater spatial variation in the different hydrological events over the Budhi Gandaki River basin. Dhunche has the 
highest number of moderate drought on May where as Dhading and Pansayakhola have the smallest number of drought days on the month of April. Samdobazar has the highest moderate wet days on July whereas Dhunche has the lowest moderate wet days on March. In the case of a very wet day event, Samdobazar has again the highest very wet days on July. Larke has the lowest very wet days on January. The findings have shown a greater spatial variation as well as seasonal variation in the highest moderate drought, moderate wet and very wet days on the basis of the months. Moreover, as there were a majority of near normal days seen in the analysis, the wetness/dryness in several stations had no much impact leading to flash floods/drought during those days over the Budhi Gandaki River Basin. If such pattern of the rainfall persists in upcoming days, the Budhi Gandaki River Basin would be safe for planning several hydroelectric power or irrigation projects for the nation like Nepal. Then, this will lead to increase the existing GDP in Nepal. However, it is necessary to think that plans and policies should be made to mitigate the impact of future extreme drought/ wet days due to climate change (if happens), so that hydroelectric power or irrigation projects would be sustainable over the basin in the future.

\section{ACINNOWLEDGEMENTS}

Author is grateful and thankful to Department of Hydrology and Meteorology, Government of Nepal for providing daily rainfall data of period 198I-20I7. Special thanks go to Mr. Suresh Marahatta, Lecturer, Tri-Chandra Multiple Campus, Kathmandu for his support in preparing this paper.

\section{CONFLICT OF INTEREST}

The author confirm that there is no conflict of interest.

\section{REFERENCES}

Abramowitz, M., \& Stegun, I. A. (1965). Handbook of Mathematical function. UK: Dover Publication Inc.

Bhaskar, B.P., Satyavati, P.L.A., \& Singh, S.K., et al. (2018). The analysis of standardized precipitation index (SPI) in cotton growing Yavatmal district, Maharashtra. Adv Plants Agric Res., 8(6), 505-510. doi: 10.15406/apar.2018.08.00376

Cancelliere, A., Rossi, G., \& Ancarani, A. (1996). Use of Palmer index as a drought indicator in Mediterranean regions. In Proc, IAHR Con! From Flood to Drought. Sun City, South Africa.

Chhikara, R. S., \& Folks, J. L. (1989). The Inverse Gaussian Distribution: Theory, Methodology and Applications. New York, USA: Marcel Dekker, Inc.

Deka, S., Boraj, M., \& S. C. (2009). Distribution of annual maximum rainfall series of North-East India. European Water, 27/28.

David, G. B. (20I2). MathWave data analysis \& simulation, MathWave Technologies. Atlas V Program, Aerospace Corp. Retrieved from https://easyfit.informer.com/5.5/ 
Edwards, D. C., \& McKee, T. B. (1997). Characteristics of 20th century drought in the United States at multiple time-scales. Department of Atmospheric Science, Colorado State University, Colorado. Retrieved from https://dspace.library.colostate.edu/handle//02/7//70176.

Hansen, J., Ruedy, R., Sato, M., \& Lo, K. (2010). Global surface temperature change. Rev. Geophysics, 48:RG4004. doi: 10.1029/2010RG000345

Hayes, M.J. (1999). Drought Indices. National Drought Mitigation Centre, Lincoln, Nebraska. Retrieved from http://enso.unl.edulnmdc.

Gaudel, Prakash. (2013). Implications of Proposed Budhi Gandaki and Upper Set Storage Projects on Nepal-India Water Relation in Changing Climate Regime (Master thesis, Pokhara University, Nepal).

Guttman, N.B. (1994). On the sensitivity of sample moments of sample size. Journal of climate, $7(6), 1026-1029$.

Guttman, N.B. (1998). Comparing the Palmer drought index and the standardized precipitation index. J. Am. Water Res. Assoc., 34(I), I1 3-121.

Guttman, N. B. (1999). Accepting the Standardized Precipitation Index: A Calculation Algorithm. JAWRA Journal of the American Water Resources Association, 35(2), 3II-322. doi:I0.1 I I I/j.1752-1688.1999.tb03592.x

Johnson, N. L. (1949). Systems of Frequency Curves Generated by Methods of translation. Biometrika, 36(I/2), 149-176. doi: 10.2307/2332539

Lana, X., Serra, C., \& Burgueno A. (200I). Patterns of monthly rainfall shortage and excess in terms of the Standardized Precipitation Index for Catalonia (NE Spain). International Journal of Climatology, 21, 1669-1691.

Mishra, A. K., \& Singh, V. P. (2010). A review of drought concepts. J. Hydrol, 39I, 202-2I6.doi: 10.1016/j.jhydol.2010.07.012

McKee, T.B, Doesken, N.J., \& Kleist, J. (1993.) The relationship of drought frequency and duration to time scales. In 8th Conference on App lied Climatology (pp. 179-184). Boston, USA: American Meteorological Society.

McKee, T.B., Doesken, N.J., \& Kleist, J. (1995). Drought monitoring with multiple time scales. In Pre-prints, Proceedings of the 9th Conference on Applied Climatology, 15-20 January 1995, (pp. 233-236). Dallas, TX, USA: American Meteorological Society.

Obasi, G.P.O. (1994). WMO's Role in the International Decade for Natural Disaster Reduction. Bulletin of American Meteorological Society, 75(9), 1655- 1662.

Papoulis, A., \& Pillai, S. U. (2002). Probability, Random Variables, and Stochastic Processes (4th Ed.). Boston: McGraw-Hill.

Pereira, L.S., Cordery, I., \& lacovides, I. (2002). Coping with water scarcity. IHP-VI, Technical Documents in Hydrology, 58, UNESCO, Paris.

Rossi, Richard J. (2018). Mathematical Statistics: An Introduction to Likelihood Based Inference. New York: John Wiley \& Sons.

Shrestha, M. L. (2000). Inter annual variation of summer monsoon rainfall over Nepal and its relation to Southern Oscillation Index. Meteorol Atmos Phys, 75, 21-28. 
Shrestha, A. B., \& Aryal, R. (2010). Climate change in Nepal and its impact on Himalayan glaciers. Regional Environmental Change, II, 65-77. doi: https://doi.org/10.1007/s I0II3-010-01749

Shrestha, M. L., Dahal, P., Shrestha, N. S., Panthi, J., Jha, A., Lakhankar, T., \& Krakauer N. Y. (20I4). Drought risk assessment in central Nepal: temporal and spatial analysis. Natural Hazards, 80 (3), 1913-1932.

Shrestha, M. L., Dahal, P., Shrestha, N. S., Panthi, J., Jha, A., Lakhankar, T., \& Krakauer, N. Y. (2016). Drought risk assessment in central Nepal: temporal and spatial analysis. Natural Hazards, 80(3), 1913-1932. doi: 10.1007/s I 1069-0I5-2055-5

Shrestha, Bhupal, Pandey, Binayak, Shrestha, Eileen, Ghimire, Sanjaya, Bhattarai, \& Shakep. (2016). Characterization of Microorganisms for Production of Bioethanol from Agriculture Wastes and Using It as Biofuel. Retrieved from https://www.researchgate. net/publication/314364337_Characterization _of_Microorganisms_for_Production_of_Bioethanol_from_Agriculture_Wastes_and_U sing_lt_as_Biofuel.

Shrestha, R. M., Sthapit, A. B., \& Shrestha, S. L. (2017). A Probabilistic Approach for Assessment of Future Drought in Bagmati River Basin, Nepal. Nepalese Journal of Statistics, 2, 75-88. doi: http://dx.doi.org//0.3126/njs.v2i0.21 I56.

Sigdel, M., \& Ikeda, M. (2010). Spatial and temporal analysis of drought in Nepal using standardized precipitation index and its relationship with climate indices. SOHAMNepal. Journal of Hydrology and Meteorology, 7(1), 59-74.

Topcu, E., \& Seckin, N. (2016). Drought analysis of the Seyhan Basin by using standardized precipitation index (SPI) and L-moments. 22, 196-2 I5. Retrieve from https://www.researchgate. net/publication/304943366.

T. Thomas; P. C. Nayak; and Narayan C. Ghosh. (20I5). Spatiotemporal Analysis of Drought Characteristics in the Bundelkhand Region of Central India using the Standardized Precipitation Index. Journal of Hydrologic Engineering, 20 (I I). Retrieved from https://ascelibrary.org/ doi/I0.106I/\%28ASCE\%29HE.1943-5584.000I I89

Vicente-Serrano, S. M., Begueria, S., \& Loòez-Moreno, J. I. (2010). A multi scaler drought index sensitivity to global warming: the standardized Precipitation Evapotranspiration Index. Journal of Climatology, 23, 1696-1718.

Valentin, A., Fränzi, K. N., \& Tobias, R. (2017). The earth is flat $(p>0.05)$ : significance thresholds and the crisis of unreplicable research. Peer], 5. doi: 10.77/7/peerj.3544

Vogt, J.V., \& Somma, F. (Eds.). (2000). Drought and Drought Mitigation in Europe. Dordrecht, Netherlands: Kluwer Academic Publishers. doi: 10.1007/978-94-0I5-9472-I_I

Wikipedia. (2020). The Wikimedia Foundation, Inc., a non-profit organization. Retrieved from https://en.wikipedia.org/w/index. php?title=Special:DownloadAsPdf \&page=Budhigandaki_Hydroelectric_Project\&action=show-download-screen.

Wilhite, D.A., Siva Kumar, M.V.K., \& Wood, D.A. (Eds.). (2000). Early warning systems for drought preparedness and drought management. Proceedings of an Expert Group Meeting, 
Lisbon, Geneva: World Meteorological Organization. Retrieved from http://drought.unl.edu/monitor/EWS/EWS_WMO.html.

Note: Supplementary material of this paper is available.

Reference to this paper should be made as follows:

Shrestha, R. M. (2020). Drought or wet assessment of the daily rainfall pattern of Budhi Gandaki basin, Nepal: Standardized precipitation index approach using probabilistic model. Nep. J. Stat, 4, 57-72. 
